\title{
A C-terminal fragment of an intron-encoded maturase is sufficient for promoting group I intron splicing
}

\author{
MAUREEN E. DOWNING, ${ }^{1}$ KRISTINA L. BRADY, and MARK G. CAPRARA \\ Center for RNA Molecular Biology, Case Western Reserve University School of Medicine, Cleveland, Ohio 44106-4960, USA
}

\begin{abstract}
Group I introns often encode proteins that catalyze site-specific DNA hydrolysis. Some of these proteins have acquired the ability to promote splicing of their cognate intron, but whether these two activities reside in different regions of the protein remains obscure. A crystal structure of I-Anil, a dual function intron-encoded protein, has shown that the protein has two pseudo-symmetric domains of equal size. Each domain contacts its DNA substrate on either side of two cleavage sites. As a first step to identify the RNA binding surface, the $\mathrm{N}$ - and $\mathrm{C}$-terminal domains of I-Anil were separately expressed and tested for promoting the splicing of the mitochondrial $(\mathrm{mt})$ COB pre-RNA. The N-terminal protein showed no splicing activation or RNA binding, suggesting that this domain plays a minimal role in activity or is improperly folded. Remarkably, the 16-kDa C-terminal half facilitates intron splicing with a rate similar to that of the full-length protein. Both the C-terminal fragment and full-length proteins bind tightly to the COB intron. RNase footprinting shows that the C-terminal and full-length proteins bind to the same regions and induce the same conformational changes in the COB intron. Together, these results show that the $\mathrm{C}$-terminal fragment of I-Anil is necessary and sufficient for maturase activity and suggests that I-Anil acquired splicing function by utilizing a relatively small protein surface that likely represents a novel RNA binding motif. This fragment of I-Anil represents the smallest group I intron splicing cofactor described to date.
\end{abstract}

Keywords: catalytic RNA; RNA-protein interactions; RNA folding

\section{INTRODUCTION}

Group I intron-encoded proteins that facilitate splicing of their cognate introns (maturases) are derived from sitespecific DNA endonucleases that promote intron mobility (homing). Maturases and their related homing enzymes contain two copies of the conserved amino acid motif designated LAGLIDADG and appear indistinguishable from one another (Chevalier and Stoddard 2001). For example, sequence analysis of maturases and dedicated endonucleases do not show evidence of inserted or appended domains to account for splicing function. In addition, half of known maturases also retain homing activity (Dalgaard et al. 1997; Lambowitz et al. 1999). Finally, comparison of the threedimensional structures between a dual function maturase/

\footnotetext{
${ }^{1}$ Present address: Department of Forensic Science, University of Illinois-Chicago, Chicago, IL 60612, USA.

Reprint requests to: Mark G. Caprara, Center for RNA Molecular Biology, Case Western Reserve University, School of Medicine, 10900 Euclid Ave., Cleveland, OH 44106-4960, USA; e-mail: mgc3@po.cwru.edu; fax: (216) 368-2010.

Article and publication are at http://www.rnajournal.org/cgi/doi/ 10.1261/rna.7225205.
}

endonuclease from Aspergillus nidulans (I-AniI) with a number of other homing endonucleases shows that both types of proteins share a conserved overall topology (Bolduc et al. 2003). While the mechanisms by which homing endonucleases recognize and cleave their target sequences are well established, how such proteins bind with high specificity to their intron RNA substrates and promote RNA splicing is only beginning to be uncovered (Ho and Waring 1999; Solem et al. 2002).

The similarity between LAGLIDADG maturases and homing endonucleases has supported the speculation that proteins use the same binding site to carry out both functions. In support of this view, there is striking similarity between the RNA structure defining the $5^{\prime}$ and 3 splice sites (P1/P10 pseudoknot) of maturase-dependent group I introns and the protein's DNA target sites (e.g., Chatterjee et al. 2003). However, recent evidence from studies on the I-AniI maturase/endonuclease encoded from the intron within the mitochondrial apocytochrome $b(\mathrm{COB})$ gene has suggested that the RNA and DNA recognition mechanisms are distinct. A series of competition experiments showed that while DNA hydrolysis is inhibited in the presence of $A$. nidulans COB pre-RNA, RNA splicing was not affected by 
the presence of I-AniI's DNA homing site (Chatterjee et al. 2003; Geese et al. 2003). Direct binding experiments confirmed that bound $A$. nidulans $\mathrm{COB}$ pre-RNA interfered with DNA binding to I-AniI but that the DNA substrate could not compete with pre-RNA binding (Chatterjee et al. 2003). These observations are consistent with the idea that I-AniI's RNA binding site, at least in part, is situated on a surface distinct from that used for DNA binding.

The finding of amino acid substitutions that uncouple DNA and RNA binding supported the possibility of independent binding sites in I-AniI. First, alanine substitutions in the seventh position in either of the conserved LALIDADG motifs abolished DNA binding but had no effect on RNA binding or splicing (Chatterjee et al. 2003). To identify possible maturase-specific positions, the sequence of I-AniI was compared to its two closest maturase relatives (VicobI5 from Venturia aequalis and cobI3 from Saccharomyces cerevisiae). This analysis revealed a series of conserved basic residues distributed across the protein, at positions removed from the DNA binding site (Fig. 1A; Bolduc et al.

$\mathbf{A}$
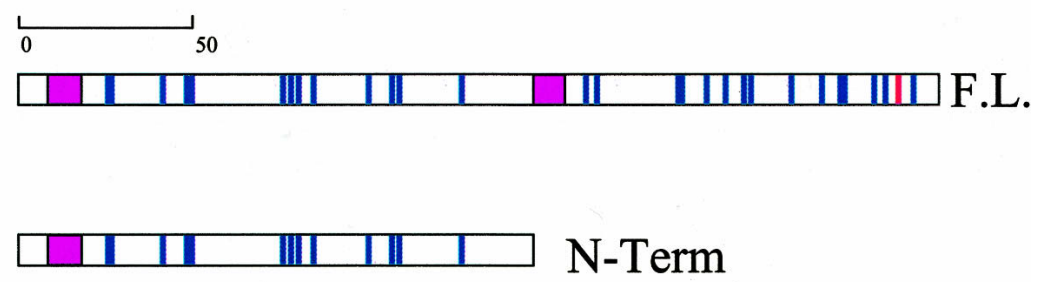

\section{पII IIIIIIIIII C-Term}

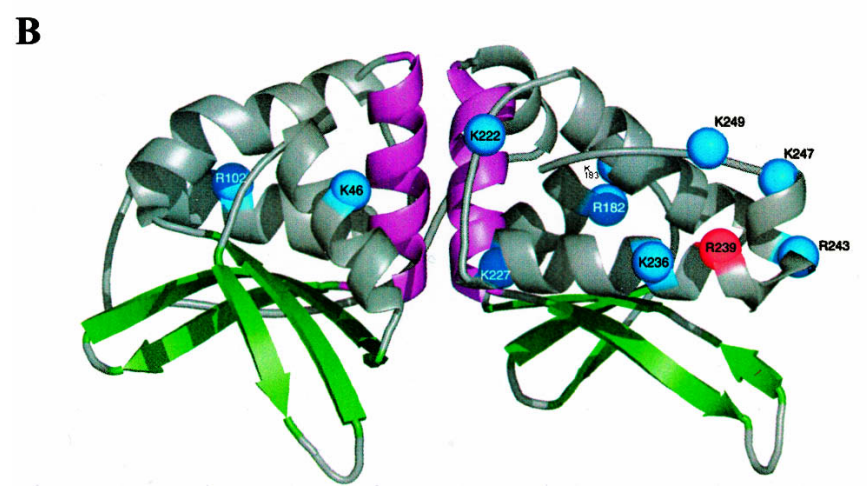

FIGURE 1. Structure of I-AniI protein. (A) Linear representation of I-AniI with the two LAGLIDADG motifs highlighted in pink. The location of the conserved basic residues is shown (blue) as is the maturase inactivating substitution (R239E; red). (Top) Full-length I-AniI (F.L.); (middle) the $\mathrm{N}$-terminal fragment (N-Term); (bottom) C-terminal fragment (C-Term). The scale represents 50 amino acids. (B) Three-dimensional structure of I-AniI. The DNA binding surface is composed of curved, green $\beta$-sheets shown at the bottom of the structure while the two pink LAGLIDADG $\alpha$-helices are in the center of the structure. This view emphasizes the possible intron RNA binding surface of the protein. Conserved, surface accessible amino acids are shown as blue spheres; the maturase-deactivating mutation site (R239) is colored red.
2003). A single glutamate substitution in one of the conserved residues (arginine 239 [R239E]) four residues from the $\mathrm{C}$ terminus resulted in a 10 -fold decrease in $A$. nidulans COB pre-RNA splicing and ribonucleoprotein (RNP) dissociation rates. In contrast, no effects on DNA binding or hydrolysis were observed (Bolduc et al. 2003). While these results suggested that the structural requirements for RNA and DNA binding are different, they did not greatly clarify location or the size of I-AniI's RNA binding site.

The linear and three-dimensional arrangement of I-AniI neatly separate the protein into approximately equal sized $\mathrm{N}$ - and C-terminal polypeptides, each beginning with one of the two LAGLIDADG motifs (Fig. 1). The conserved

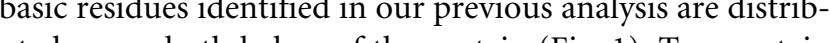
if we expressed and purified each half separately. Here we show that the N-terminal protein shows no RNA splicing facilitation or binding activity. Remarkably, the small 16kDa C-terminal fragment not only specifically binds the $A$. nidulans $\mathrm{COB}$ pre-RNA but is sufficient for promoting its splicing.

\section{RESULTS}

\section{Expression and splicing activity of the $\mathrm{N}$ - and $\mathrm{C}$-terminal polypeptides}

The I-AniI N- and C-terminal fragments were insoluble when expressed independently. Subsequently, both halves were expressed as fusion proteins with an upstream NusA transcriptional cofactor. NusA functions well as a "carrier" protein for expressing insoluble target proteins in soluble form (Harrison 2000). These constructs gave high levels of soluble proteins that were purified by Ni-NTA affinity chromatography and showed no DNA target site binding activity as expected (data not shown).

To test whether the protein fragments promoted intron splicing, we incubated the fusion proteins with $5^{\prime}$-end-labeled A. nidulans COB pre-RNA (Fig. 2A). After only $1 \mathrm{~min}$ of incubation, the Cterminal protein showed comparable splicing activity to the full-length I-AniI protein (cf. lanes 3 and 11). Importantly, the NusA protein alone showed no COB pre-RNA splicing or binding activity (data not shown), indicating that the splicing activity of the fusion protein was due to the presence of the 
A

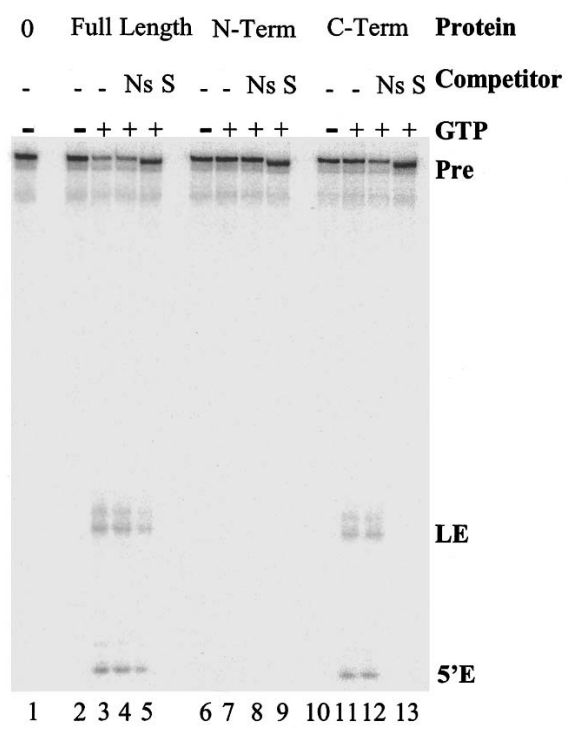

B

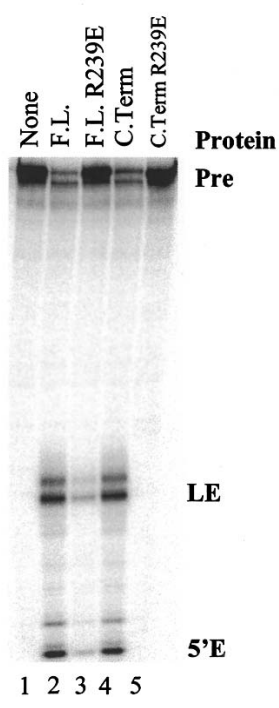

FIGURE 2. Splicing activity of I-AniI, N- and C-terminal proteins. (A) Competition reactions with unlabeled group I introns. 5'-End-labeled A. nidulans COBme pre-RNA (50 nM) was preincubated in buffer with or without competitor RNAs $(700 \mathrm{nM})$ for $10 \mathrm{~min}$ and the reaction initiated by the addition of protein $(100 \mathrm{nM})$. The reactions were terminated by the addition of EDTA after 1 min. (Full Length) full length I-AniI; (N-Term) NusA-N-terminal fragment fusion; (C-Term) NusA-C-terminal fragment fusion; (Ns) nonspecific competitor (N. crassa LSU pre-RNA); (S) specific competitor (A. nidulans COBme pre-RNA). (B) Splicing activity of I-AniI and C-terminal protein with a maturase inactivating substitution. $5^{\prime}$-End-labeled $A$. nidulans COBme pre-RNA $(4 \mathrm{nM})$ was preincubated in buffer and the reaction initiated by the addition of protein $(150 \mathrm{nM})$. The reactions were terminated by the addition of EDTA after 15 min. (F. L.) full-length I-AniI, (F.L.R239E) full-length I-AniI with the 239 arginine to glutamate substitution; (C-Term) NusA-C-terminal fragment; (C-Term R239E) NusA-C terminal fragment fusion with the 239 arginine to glutamate substitution. (Pre) precursor RNA; (LE) ligated exons; (5'E) free $5^{\prime}$ exon. Note that the band above the $5^{\prime}$ exon is generated by cleavage of an alternative $5^{\prime} \mathrm{SS}(\mathrm{U}+2$ in the intron). The band above the ligated exons is generated by ligation of this alternative $5^{\prime}$ exon to the $3^{\prime}$ exon.

C-terminal fragment. In contrast, no maturase activity was observed for the $\mathrm{N}$-terminal protein fragment even with incubations lasting up to $60 \mathrm{~min}$ (Fig. 2A; data not shown). The specificity of the C-terminal fragment for the A. nidulans $\mathrm{COB}$ pre-RNA was assessed by including a 40 -fold molar excess of either a nonspecific or specific RNA competitor in the splicing reaction (Fig. 2A). Splicing was inhibited by the inclusion of unlabeled $A$. nidulans $\mathrm{COB}$ preRNA, as expected, but not by the presence of the noncognate Neurospora crassa LSU group I intron (Fig. 2A). These results demonstrate that splicing promoted by the C-terminal protein fragment is due to a specific interaction with the COB intron.

As discussed in the Introduction, a single mutation (R239E) in the C terminus of I-AniI affects maturase activity but has no effect on DNA endonuclease function (Bolduc et al. 2003; Fig. 2B). The same mutation significantly reduced the ability of the C-terminal fragment to promote $\mathrm{COB}$ splicing, suggesting that the protein requirements for splicing activation are similar to those for the full-length I-AniI (Fig. 2B). Taken together, these data are consistent with the $\mathrm{C}$ terminus of I-AniI being largely re-

sponsible for the specificity and activation of $A$. nidulans $\mathrm{COB}$ intron splicing.

To help define the minimal active maturase peptide, we planned to test smaller fragments of the C-terminal protein. However, the position of the maturase-inactivating R239E mutation is only four residues from the $\mathrm{C}$ terminus end and therefore the protein cannot be significantly shortened from this end. Furthermore, deletion of the C-terminal LAGLIDADG motif resulted in an inactive protein (data not shown). Thus, the C-terminal fragment described above is the smallest active maturase peptide from I-Anil. To gain deeper insight into the maturase activity of this peptide, we compared the properties of the C-terminal fragment/A. nidulans COB pre-RNA complex with those of the full-length I-AniI/A. nidulans $\mathrm{COB}$ pre-RNA complex.

\section{Properties of the $\mathrm{C}$ terminus/A. nidulans COB pre-RNA complex}

To compare the efficiency of splicing facilitation between I-AniI and the C-terminal fragment, we carried out timecourse experiments. Figure 3 shows that with saturating protein concentrations, both $\mathrm{I}-\mathrm{A} n \mathrm{iI}$ and the $\mathrm{C}$ terminus protein facilitate $A$. nidulans $\mathrm{COB}$ pre-RNA splicing with similar, biphasic kinetics. The majority of the A. nidulans COB pre-RNA in the presence of either protein spliced at a fast rate while the remainder spliced more slowly. As discussed elsewhere, the slow splicing species may represent a population of RNA that undergoes a slow folding step required for RNA catalysis or protein binding (Solem et al. 2002). In the presence of full-length protein, $90 \%$ of the $A$. nidulans COB pre-RNA spliced at a rate of 2.1 $\min ^{-1}$ (Solem et al. 2002; Fig. 3). When bound by the C-terminal protein, $70 \%$ of the A. nidulans COB pre-RNA spliced at a rate of $0.6 \mathrm{~min}^{-1}$, only $\sim 3.5$-fold slower than the full-length protein.

The affinities of the C-terminal and $\mathrm{N}$-terminal proteins for the A. nidulans COB pre-RNA and the stability of the complexes were assessed by measuring the apparent equilibrium constant $\left(K_{d}^{\text {app }}\right)$ and dissociation rate $\left(k_{\text {off }}\right)$ by nitrocellulose binding experiments (Fig. 4A,B). Equilibrium binding experiments for full-length I-AniI do not report the same $K_{d}$ as that calculated from $k_{\text {off }} / k_{\text {on }}(\sim 50 \mathrm{pM}$; Solem et al. 2002) for technical and mechanistic reasons, but is a rapid and useful assay to estimate relative affinities between mutant proteins or intron RNAs (see Materials and Meth- 


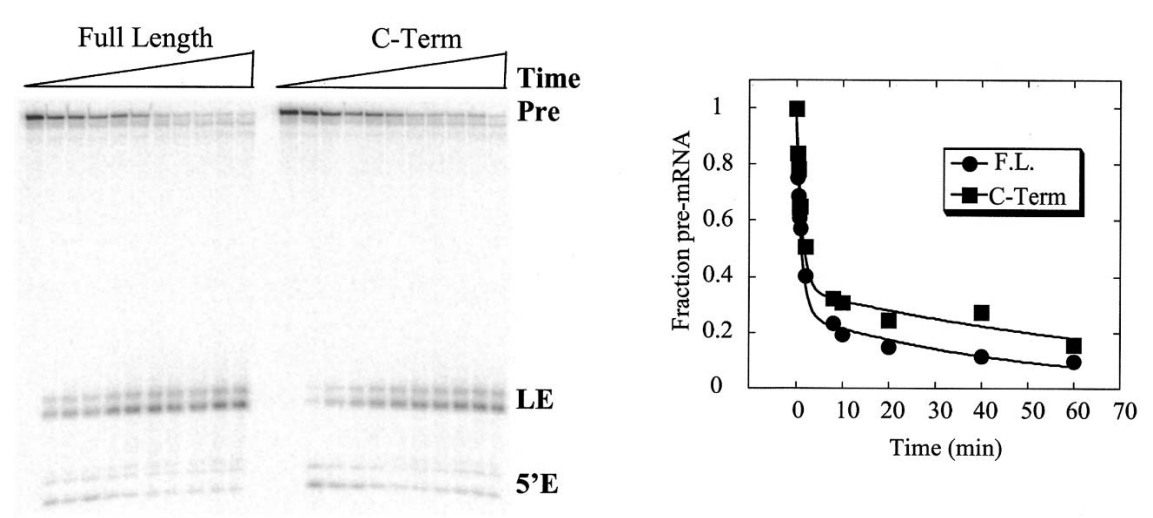

FIGURE 3. Splicing kinetics of the C-terminal protein/A. nidulans COBme pre-mRNA complex. A. nidulans $\mathrm{COBme}$ pre-RNA $(4 \mathrm{nM})$ was preincubated in buffer at $37^{\circ} \mathrm{C}$ and the reaction initiated by the addition of protein $(500 \mathrm{nM})$. The plot at the right shows the fraction of $A$. nidulans COBme pre-RNA remaining versus time. The data were fit to a double exponential with the fast phase describing $90 \%$ or $70 \%$ of the reactive RNA for the full-length and Cterminal fragment proteins, respectively. The average splicing rate of the $\mathrm{C}$-terminal fragment bound RNA for three independent determinations is $0.61( \pm 0.14) \mathrm{min}^{-1}$ while for I-AniI it is $2.1( \pm 0.48) \mathrm{min}^{-1}$ (Solem et al. 2002). (Pre) precursor RNA; (LE) ligated exons; (5'E) free 5' exon.

ods). For the equilibrium binding assays, trace amounts of ${ }^{32} \mathrm{P}$-labeled pre-RNA were incubated with increasing protein concentrations and filtered. A plot of the fraction of bound RNA as a function of protein concentration showed that the full-length protein has a $K_{d}^{\text {app }}$ of $12 \mathrm{nM}$ while the C-terminal polypeptide binds approximately fourfold more weakly with a $K_{d}^{\text {app }}$ of $50 \mathrm{nM}$. The binding to the $A$. nidulans $\mathrm{COB}$ pre-RNA represents a specific complex, as the C-terminal protein showed barely detectable binding to the noncognate $N$. crassa LSU intron (Fig. 4A). In contrast to binding by the $\mathrm{C}$-terminal protein, the $\mathrm{N}$-terminal fragment of I-AniI bound poorly to the A. nidulans COB pre-RNA (Fig. 4A). These data demonstrate that specific RNA binding is mediated through the C-terminal region of I-AniI.

Dissociation experiments were carried out by binding ${ }^{32} \mathrm{P}$-labeled A. nidulans COB pre-RNA with protein, diluting the complex in the presence of unlabeled RNA, and filtering aliquots at various times. It was previously shown that the COB pre-RNA/full length I-AniI complex shows biphasic dissociation behavior, with $20 \%$ of the complexes dissociating rapidly $\left(k_{\text {off }}=0.4 \mathrm{~min}^{-1} ; t_{1 / 2}=1.7 \mathrm{~min}\right)$ while the remainder dissociated much more slowly $\left(k_{\text {off }}=0.012\right.$ $\min ^{-1} ; t_{1 / 2}=58 \mathrm{~min}$; Solem et al 2002; Fig. 4B). The C terminus/COB pre-RNA complexes also dissociated in two phases; however, the majority (68\%) dissociated quickly ( $k_{\text {off }}=0.20 \mathrm{~min}^{-1} ; t_{1 / 2}=3.5 \mathrm{~min}$ ). The slowly dissociating species $(32 \%$ of the complexes) dissociated with a rate equivalent to the full-length I-AniI $\left(k_{\text {off }}=0.010 \mathrm{~min}^{-1}\right.$; $t_{1 / 2}=69 \mathrm{~min}$ ). This dissociation rate is close to the rate of C-terminal fragment facilitated splicing under conditions where protein dissociation is rate limiting $\left(k_{\text {splice }}=0.004\right.$ $\mathrm{min}^{-1}$; Fig. 4C; Solem et al. 2002). Thus, the slowly dissociating species in the $k_{\text {off }}$ experiments likely represents the splicing competent complex. The increase in proportion of fast dissociating complexes for the C-terminal protein may reflect that a large percentage of intron bound protein is improperly folded in the absence of the $\mathrm{N}$ terminus.

\section{C-terminal protein binding and intron RNA folding}

Ribonuclease probing was used to compare binding sites of I-AniI and the Cterminal protein as well as to characterize the RNA structural changes that accompany assembly of each respective RNP. Using 5' end-labeled RNAs, regions accessible to ribonuclease 1 (specific for single-stranded RNA) or V1 (specific for double-stranded RNA) cleavage were mapped without protein at $5 \mathrm{mM} \mathrm{Mg}^{2+}$, as well as in the presence of either protein (Fig. 5A,B). At $5 \mathrm{mM}$ $\mathrm{Mg}^{2+}$, in the absence of protein, many predicted singlestranded and helical regions were cleaved by RNase 1 and V1, respectively. However, extensive RNase 1 but not V1 cleavage of the P7 and P9 helices is consistent with instability of these key components of the catalytic core. In addition, RNase 1 cleaved many conserved single-stranded joining regions that should be protected by the folded intron core (e.g., J3/4, J4/5, and J8/7) as shown in the threedimensional structures of the Tetrahymena and Azoarcus self-splicing group I introns (Golden et al. 1998; Adams et al. 2004). Taken together the cleavage patterns at $5 \mathrm{mM}$ $\mathrm{Mg}^{2+}$ are suggestive of an unfolded or partially folded RNA, as was concluded on the basis of RNase T1 cleavage of a slightly different $A$. nidulans COB pre-RNA (Ho and Waring 1999). Disruption of the intron core accounts for the lack of self-splicing for the $A$. nidulans $\mathrm{COB}$ pre-RNA in the absence of I-AniI.

Binding of either the full-length or C-terminal protein resulted in identical digestion patterns in the A. nidulans COB pre-RNA. In both cases, the patterns were consistent with folding of the intron into a functional conformation. In particular, helices P7 and P9 and key single-stranded joining regions mentioned above become protected from RNase 1 cleavage. In addition, protection of the $5^{\prime}$ strands of P3 and P4 from V1 cleavage is consistent with these helices packing against $\mathrm{P} 6$ and $\mathrm{P} 7$ in the folded intron structure as observed for the Tetrahymena and Azoarcus introns (Golden et al. 1998; Adams et al. 2004). Finally, two enhanced V1 cleavages are observed at the base of the P6a and P5 helices, suggesting that these sites are not in contact with the proteins but, rather, are stabilized by protein binding. Taken together, these data indicate that the full-length and C-terminal proteins induce the same conformational 
$\mathbf{A}$

B
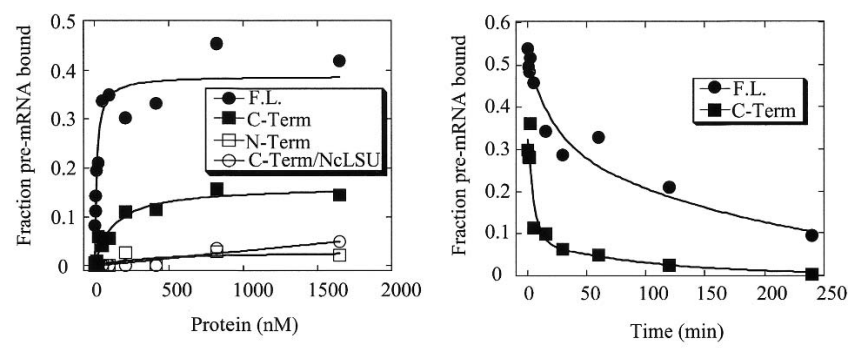

C

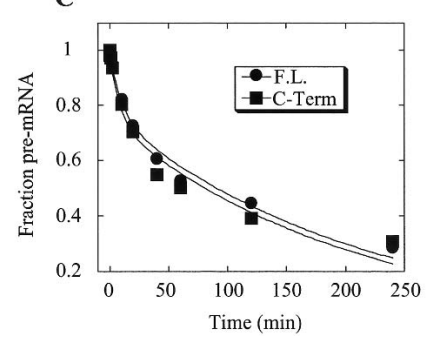

FIGURE 4. Binding of I-AniI, N-, and C-terminal fragment proteins. (A) Equilibrium binding. Trace amounts of ${ }^{32} \mathrm{P}$-labeled $A$. nidulans COBme pre-RNA were incubated with a range of protein concentrations and filtered. The data were fit to: Fraction RNA bound $=A \times E /$ $\left(E+K_{d}^{\text {app }}\right)$ where $A$ is the total amplitude bound and $E$ is the concentration of I-AniI and $K_{d}^{\text {app }}$ is the apparent equilibrium dissociation constant. The experiment was repeated three times to yield a $K_{d}^{\text {app }}$ of $12.3( \pm 2.1) \mathrm{nM}$ and $50( \pm 17) \mathrm{nM}$ for the full-length I-AniI and Cterminal protein, respectively. Note that the filter retention efficiency of the C-terminal fragment in this assay $(\sim 10 \%)$ causes the amplitude to be approximately threefold less than that for the full-length protein. (B) $k_{\text {off }}$ determination for the C-terminal protein. Dissociation of the A. nidulans $\mathrm{COBme}$ pre-RNA/protein complexes was initiated by dilution in RNA binding buffer containing an 800-fold molar excess of unlabeled to labeled $A$. nidulans COBme pre-RNAs followed by filtration at the times indicated. The data for the $\mathrm{C}$-terminal protein were fit to a double exponential with $68 \%$ of the complex dissociating rapidly and $32 \%$ dissociating more slowly. The dissociation rate constant was determined from two independent experiments. The $k_{\text {off }}$ of the fast phase is 0.20 (range $0.18-0.21$ ) $\mathrm{min}^{-1}$ and for the slow phase is 0.01 (range $0.009-0.01$ ) $\mathrm{min}^{-1}$. A plot of an experiment with the full-length I-AniI performed at the same time is shown as a control. (C) Turnover kinetics of the splicing reaction. A. nidulans COBme pre-RNA $(270 \mathrm{nM})$ was incubated in buffer and the reaction initiated by the addition of protein $(90 \mathrm{nM})$. Under these conditions, the protein is saturated with pre-RNA substrate and the observed rate of splicing reflects primarily the dissociation of the complex (Ho and Waring 1999; Solem et al. 2002). The average splicing rate of the C-terminal fragment bound RNA for three independent determinations is $0.004( \pm 0.002) \mathrm{min}^{-1}$ while for I-AniI it is 0.01 (range $0.02-$ 0.008) $\min ^{-1}$ (Solem et al. 2002).

changes in the $\mathrm{COB}$ intron. Furthermore, since the C-terminal fragment protection patterns are identical to those of the full-length I-AniI, it is probable that the $\mathrm{C}$ terminus contains most (if not all) of the maturase RNA binding surface.

\section{DISCUSSION}

Group I intron maturases represent an interesting class of RNA binding proteins that promote folding of their cognate introns. One key to understanding how they achieve such specificity and induce a functional RNA structure is to define the protein surface required for maturase activity. Here we have defined the smallest contiguous fragment $(16 \mathrm{kDa})$ from I-AniI that both binds to and facilitates splicing of the COB pre-RNA. Surprisingly, more than half of the protein can be dispensed with, making this fragment of I-AniI the smallest known group I intron splicing cofactor described to date.

\section{C terminus of I-Anil is sufficient for maturase activity}

The N-terminal fragment of I-AniI does not promote splicing of and binds very weakly to the $A$. nidulans $\mathrm{COB}$ preRNA. While negative results such as these may be explained by an improperly folded N-terminal protein, the robust splicing and binding activity of the C-terminal fragment of I-AniI suggests that the $\mathrm{N}$ terminus plays, at best, only a small direct role in the protein's maturase function.

The C-terminal fragment recognizes and promotes splicing of $A$. nidulans $\mathrm{COB}$ pre-RNA in a manner analogous to the full-length protein. The rate of $A$. nidulans COB preRNA splicing in the presence of saturating $C$ terminus concentrations is only modestly slower than the full-length protein. Also, the same amino acid substitution that reduces the wild-type maturase activity also reduces the C-terminal protein activity, suggesting that the mechanism of splicing activation is the same for both proteins. The fact that the C-terminal fragment's activity closely parallels the fulllength protein presents a strong case that the $\mathrm{C}$ terminus of $\mathrm{I}-$ AniI is largely responsible for splicing activation.

The C-terminal half of the protein contributes significantly to overall RNA binding affinity and specificity. The apparent equilibrium constant of the C-terminal fragment of A. nidulans COB pre-RNA is within fourfold of the fulllength protein. In addition, the $\mathrm{C}$-terminal protein, like the wild-type I-AniI, binds only weakly to a noncognate group I intron, showing that $A$. nidulans $\mathrm{COB}$ pre-RNA binding is highly specific. Kinetic experiments show that both the fulllength and C-terminal proteins form stable complexes with the A. nidulans COB pre-RNA that are characterized by half-lives of $\sim 1 \mathrm{~h}$. The finding that the truncated protein/ pre-RNA complex is as stable as the wild-type complex suggests that most of the full-length protein's RNA binding site is located in the $\mathrm{C}$ terminus. The identical RNase protection patterns for the $A$. nidulans COB pre-RNA bound by either the full-length or $\mathrm{C}$-terminal protein supports this view. However, two thirds of the C-terminal/pre-RNA complexes dissociate rapidly, suggesting that a large proportion of the bound protein is unable to bind productively with the RNA. The most likely explanation is that a significant fraction of the C-terminal protein is misfolded in the absence of the $\mathrm{N}$ terminus of I-AniI.

The conserved basic residues identified from sequence comparison of I-AniI with two of its closest relatives are 
$\infty$
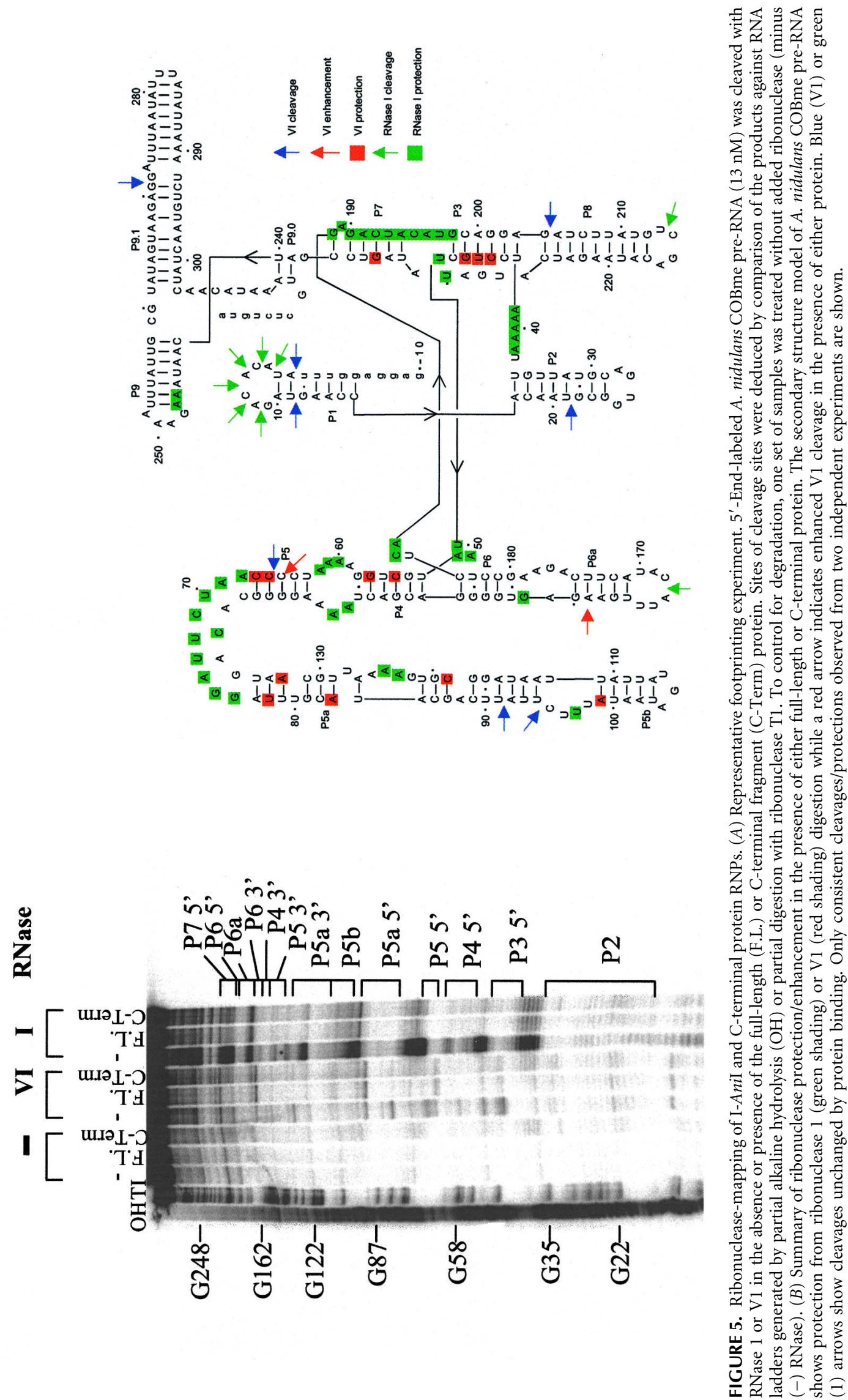
spread evenly through both the $\mathrm{N}$ - and C-terminal halves (Bolduc et al. 2003; Fig. 1). However, solvent surface area calculations show that of the 28 residues identified in the previous analysis, only 11 have their side chains fully exposed on the surface of the protein (Fig. 1B; B.L. Stoddard, unpubl.). Intriguingly, nine of these residues are located on one side of the $\mathrm{C}$ terminus raising the possibility that they function in intron binding. With the exception of K227, neither the identity nor the charge of these residues is conserved in all (8) identified intron proteins with maturase activity. This may suggest that other maturases recognize and facilitate splicing of their cognate introns in diverse ways (M.G. Caprara, unpubl.; see below).

The topology of the C-terminal half of I-AniI is $\alpha \beta \beta \alpha \beta \beta \alpha \alpha$ and does not appear structurally analogous to any known RNA binding motif. The conserved basic residues do not form a closely knit pocket of positive charge that would be suggestive of an RNA binding site (Fig. 1B). Presumably other positions surrounding these residues are involved in binding, perhaps through making hydrogen bonds and/or hydrophobic interactions with bases in the RNA. Mutagenesis and site-specific photoaffinity cross-linking will be required to define the RNA binding site more precisely. Nevertheless, our current observations are consistent with the idea that the C-terminal fragment of I-AniI represents a novel RNA binding motif that discriminates in an as yet unknown way against noncognate RNAs and promotes folding of the much larger COB pre-RNA.

\section{Structural requirements for other maturases}

The finding that the $\mathrm{C}$ terminus of I-AniI is necessary and sufficient for maturase activity is consistent with "domain" swapping experiments with the S. cerevisiae bI4 maturase and wild-type aI $4 \alpha$ endonuclease that share extensive amino acid conservation (Delahodde et al. 1989). The analysis of hybrid proteins in vivo showed that while an $\mathrm{N}$-terminal aI $4 \alpha / \mathrm{C}$-terminal bI4 protein has robust RNA maturase activity, an N-terminal bI4/C-terminal aI4 $\alpha$ protein has only weak maturase activity (Goguel et al. 1992). In addition, there have been other clues that the C-terminal regions of other maturases are important for splicing activity. First, the aI $4 \alpha$ endonuclease functions as a latent maturase in the splicing of the aI $4 \alpha$ and bi4 introns in two different mutant strains (Dujardin et al. 1982; Labouesse et al. 1987). Substitutions in the third or ninth positions of the first LAGLIDADG motif abolish endonuclease activity while substitutions in the same positions of the second, C-terminal, motif only affect maturase activity (Henke et al. 1995). Second, a missense mutation in the second LAGLIDADG motif of the Saccharomyces capensis bi2 maturase/endonuclease abolishes splicing and endonuclease activities, while a second site revertent in the C-terminal domain specifically restores maturase activity (Jamoussi and Lazowska
2000). Taken together, these observations support an important role of the C-terminal region in other maturases.

An interesting question raised by this work is whether the $\mathrm{N}$-terminal region of other maturases also plays a minimal role in splicing facilitation. There is sparse data in this regard; however, directed missense mutations have been constructed in the N-terminal LAGLIDADG motif for both the bifunctional aI $4 \alpha$ and bi2 maturase/endonuclease yeast proteins and their splicing activity tested in vivo. An $\alpha$-helix destabilizing substitution in the N-terminal motif of aI $4 \alpha$ has no effect on its maturase function (Henke et al. 1995). However, an identical substitution in the bi2 protein abolishes its maturase activity (Szczepanek et al. 2000). The differences in sensitivity to N-terminal mutations may reflect that maturases do not represent a single "family" and may have developed diverse strategies to recognize and facilitate splicing of their cognate introns, including contributions from one or both domains. In support of this hypothesis, maturase binding is not sufficient for promoting RNA splicing in some cases (e.g., Bassi et al. 2002). In these situations, other proteins cooperate with maturases to activate splicing of their cognate introns, and this may suggest that folding pathways promoted by individual maturases are different. A more thorough analysis with other maturase systems will resolve how structurally and functionally related maturases truly are.

\section{Evolutionary perspective}

The splicing activation of many group I introns by proteins is often an ancillary function. As discussed elsewhere, these cofactors are thought to have adapted to splicing by recognizing structural features in group I introns that resemble their normal substrates (Akins and Lambowitz 1987; Lambowitz and Perlman 1990). In the cases of two tRNA synthetases, it has been found that their splicing activity is indeed related to their primary functions. The N. crassa mt tyrosyl RS facilitates splicing of a number of mt group I introns by binding to the intron core via its tRNA binding surface (Caprara et al. 1996; Myers et al. 2002). Likewise, the $S$. cerevisiae mt leucyl RS, which is involved in the processing of at least two mt yeast introns, promotes splicing via a domain that functions in the editing of misactivated amino acids and binding of the tRNA acceptor helix (Herbert et al. 1988; Li et al. 1996; Rho et al. 2002). This domain may recognize an intron structure analogous to the tRNA acceptor helix.

Sequence analysis of all identified maturases does not reveal conserved motifs beyond those found in LAGLIDADG endonucleases, and therefore it has been speculated that their splicing activity is related to their original homing function. Homing endonucleases are tolerant of base-pair substitutions within their binding sites, allowing the proteins to recognize closely related, noncognate sequences. Thus, it was previously suggested that maturase function is 
derived from this flexibility of their DNA binding sites since there are strong sequence similarities between DNA target sites and the exon/intron structures in group I introns (for review, see Lambowitz et al. 1999; see the Introduction). However, in contrast to the prevailing adaptation hypothesis, I-AniI appears to facilitate splicing by utilizing a surface distinct from that for DNA binding (Bolduc et al. 2003; Chatterjee et al. 2003). As shown here, most of the maturase surface is contained within the region between the second LAGLIDADG motif and a nonconserved loop containing R239 at the end of the protein (Bolduc et al. 2003). Thus, I-AniI, and perhaps other maturases, adapted to function in splicing by co-evolution between the intron and a relatively small protein surface. This adaptation had few structural costs as I-AniI (and at least half of the known maturases) maintains its endonuclease function. In this regard, the development of maturase function from a preexisting structure may be pertinent to other single domain proteins that have evolved to perform two or more functions (Jeffery 2003).

\section{MATERIALS AND METHODS}

\section{Cloning the $\mathrm{N}$ - and $\mathrm{C}$-terminal NusA fusion genes and protein purification}

The N- and C-terminal gene fragments were cloned into pET44a (Novagen), an expression plasmid that includes the NusA gene upstream of a multiple cloning site and an $\mathrm{N}$-terminal $\mathrm{His}_{6}$-tag for protein purification. The fragments were made by polymerase chain reaction (PCR) with Pfx DNA Polymerase (Invitrogen), using primers that flanked the regions of interest from plasmid $\mathrm{pB} 12$ or pB12239E that contain the wild-type or R239E I-AniI gene (see Fig. 1). PCR products were cloned into the BamHI and HindIII sites of pET44a. Positive clones were sequenced completely. The clones were transformed into BL21 (DE3) cells and proteins expressed and purified as described (Solem et al. 2002).

\section{RNA synthesis}

A. nidulans $\mathrm{COB}$ introns containing pre-RNAs were transcribed from either BamHI digested pT7AnCOBme or from a PCR product using oligonucleotides COB5E and COB3E. Both templates yield the same A. nidulans COBme pre-RNA (Solem et al. 2002). $N$. crassa LSU group I intron pre-RNA (used as the nonspecific RNA) was transcribed from plasmid pBD5a digested with BanI (Saldanha et al. 1995). Transcription included $\sim 3 \mu \mathrm{g}$ of DNA template in buffer containing $0.5 \mathrm{mM}$ rGTP, $1 \mathrm{mM}$ rUTP, $1 \mathrm{mM}$ rATP, $1 \mathrm{mM}$ rCTP (Amersham Biosciences), $0.2 \mathrm{U} / \mu \mathrm{L}$ RNase OUT (Invitrogen), $1.11 \mathrm{mM}$ guanosine, and T7 (T3 in the case of pBD5a) RNA polymerase. DNase I (20 units; Stratagene) was added to remove the template DNA and the reactions were extracted with phenol:chloroform:isoamyl alcohol solution (25:24:1; PCI), purified by centrifugation through a Sephadex G-50 spun column (Sigma Chemical Co.), precipitated with ethanol, and resuspended in water.
RNAs to be $5^{\prime}$ end labeled were incubated in buffer with T4 polynucleotide kinase (New England Biolabs) and $\left[\gamma-{ }^{32} \mathrm{P}\right]-\mathrm{ATP}$ $(6,000 \mathrm{Ci} / \mathrm{mmol}$; Perkin Elmer). The reactions were incubated at $37^{\circ} \mathrm{C}$ for $45 \mathrm{~min}$, extracted with PCI, and centrifuged through a Sephadex G50 column. The labeled RNAs were purified by denaturing electrophoresis as described (Solem et al. 2002).

\section{In vitro splicing assays}

To denature the RNA, 5'-end-labeled A. nidulans COBme was heated at $95^{\circ} \mathrm{C}$ for $20 \mathrm{sec}$ and placed immediately on ice. The RNA (final concentrations as indicated in the figure legends) was added to TNM buffer ( $50 \mathrm{mM}$ Tris- $\mathrm{HCl}$ at $\mathrm{pH} 7.5,100 \mathrm{mM} \mathrm{NaCl}, 5 \mathrm{mM}$ $\mathrm{MgCl}_{2}$ ), containing $0.7 \mathrm{mM} \mathrm{GTP}, 10 \mathrm{mM}$ DTT, $1.3 \mathrm{U} / \mu \mathrm{L}$ RNase OUT (Invitrogen) and $0.67 \mathrm{mg} / \mathrm{mL}$ yeast tRNA (Sigma). The mixes were incubated at $37^{\circ} \mathrm{C}$ for $10 \mathrm{~min}$. The reactions were initiated by the addition of protein and terminated by the addition of EDTA to a final concentration of $67 \mathrm{mM}$, followed by organic extraction. Samples were electrophoresed on a $6 \%$ acrylamide/7 M urea gel, dried, and exposed on a phosphorimager screen and visualized/quantitated using a PhosphorImager 445 SI (Molecular Dynamics).

\section{RNA binding assays}

For equilibrium-binding measurements, $0.3-0.4 \mathrm{nM}{ }^{32} \mathrm{P}$-labeled A. nidulans COBme pre-RNA was incubated with $0-2.5 \mu \mathrm{M}$ protein in $50 \mu \mathrm{L}$ TNM buffer supplemented with $0.4 \mu \mathrm{g}$ tRNA/ $\mu \mathrm{L}, 10$ mM DTT, $10 \%$ glycerol (binding buffer) at $37^{\circ} \mathrm{C}$. The complexes were filtered after $20 \mathrm{~min}$ through nitrocellulose (BA45; Schleicher and Schuell), washed with $3 \mathrm{~mL}$ of buffer, dried, and counted using a Beckman LS6800 scintillation counter (Beckman Instruments). The data were fit to an equilibrium equation: Fraction RNA bound $=A \times E /\left(E+K_{d}^{\text {app }}\right)$ where $A$ is the total amplitude bound and $E$ is the concentration of I-AniI and $K_{d}^{\text {app }}$ is the apparent equilibrium dissociation constant.

Equilibrium binding experiments for full-length I-AniI do not report the same $K_{d}$ as that calculated from $k_{\text {off }} / k_{\text {on }}$ (Solem et al. 2002; Chatterjee et al. 2003). This is most likely due to intermediates in the binding pathway (Solem et al. 2002) and protein instability during incubation times required to reach equilibrium (for discussions, see Rose and Weeks 2001; Chatterjee et al. 2003). However, the experiments are a rapid and useful assay to ascertain binding specificity and estimate relative affinities between mutant proteins or intron RNAs. For example, the $K_{d}^{\text {app }}$ ranges from $\sim 10$ $\mathrm{nM}$ for $A$. nidulans COB pre-RNA to $2.5 \mu \mathrm{M}$ for a nonspecific RNA (Fig. 4A; Chatterjee et al. 2003). Mutant RNAs have been found to have $K_{d}^{\text {app }}$ s that lie between these two extremes (Chatterjee et al. 2003).

For $k_{\text {off }}$ measurements, $1 \mathrm{nM}{ }^{32} \mathrm{P}$-labeled RNA was pre-incubated in $50 \mu \mathrm{L}$ of TNM supplemented with $10 \%$ glycerol, 0.1 $\mathrm{mg} / \mathrm{mL} \mathrm{BSA}$, and $10 \mathrm{mM}$ DTT (TNMGBD) at $37^{\circ} \mathrm{C}$ for $20 \mathrm{~min}$. Complexes were formed by addition of I-AniI to $30 \mathrm{nM}$ and incubated for $5 \mathrm{~min}$. The reaction mixture was then mixed with 1 $\mathrm{mL}$ of TNMGBD containing $100 \mathrm{nM}$ unlabeled A. nidulans COBme pre-RNA to bind unassociated protein. At different times after mixing, $90 \mu \mathrm{L}$ were filtered through nitrocellulose, washed with $3 \mathrm{~mL}$ of TN, dried, and counted using a scintillation counter. 
The data were fit to a first order equation with a double exponential: Fraction RNA bound $=A\left(e^{-k t}\right)+\mathrm{B}\left(e^{-k t}\right)$ where $A$ and $B$ are the amplitude of RNA in each phase and $k$ represents the first order rate constants for each phase.

\section{RNase footprinting}

For footprinting reactions $5^{\prime}$-end-labeled RNA $(\sim 13 \mathrm{nM})$ was added to TNM buffer and incubated at $37^{\circ} \mathrm{C}$ for $10 \mathrm{~min}$. Protein or protein dilution buffer was added to the reaction and incubated for $2 \mathrm{~min}$. The concentration of full-length I-AniI was $200 \mathrm{nM}$ and the C-terminal fragment was $500 \mathrm{nM}$. After incubation with the protein, $15 \mu \mathrm{L}$ of the reaction were added to $3 \mu \mathrm{L}$ water, RNase I, or RNase VI. The final concentration of RNase I was $0.5 \mathrm{U} / \mu \mathrm{L}$ and RNase VI was $2.5 \times 10^{-4} \mathrm{U} / \mu \mathrm{L}$. After $5 \mathrm{sec}, 3 \mu \mathrm{L}$ of aurintricarboxylic acid $(50 \mathrm{mg} / 10 \mathrm{~mL}$ in $50 \mathrm{mM}$ Tris: $\mathrm{HCl}$ at $\mathrm{pH} 7.5)$ were added to terminate the reactions and the samples were extracted with PCI. The samples were electrophoresed on a series of $6 \%$ acrylamide/7 $\mathrm{M}$ urea gels that were dried and quantitated with a PhosphorImager (Molecular Dynamics). After subtracting the background, the band intensities were normalized for the amount of full-length RNA in each lane. Protections or enhancements in the presence of protein were assigned based on the change in band intensity relative to an unbound RNA sample in TNM in parallel. A position was considered protected or enhanced if the band intensity was less or greater than twofold of that in the unbound RNA sample, respectively.

\section{ACKNOWLEDGMENTS}

We thank Barry L. Stoddard (Fred Hutchison Cancer Research Center) for sharing unpublished data and making Figure 1B. We thank B.L.S., Pieter deHaseth, and Timothy W. Nilsen (CWRU) for critical reading of the manuscript. National Institutes of Health grant GM-62853 to M.G.C. supported this work.

Received November 2, 2004; accepted January 6, 2005.

\section{REFERENCES}

Adams, P.L., Stahley, M.R., Kosek, A.B., Wang, J., and Strobel, S.A. 2004. Crystal structure of a self-splicing group I intron with both exons. Nature 430: 45-50.

Akins, R.A. and Lambowitz, A.M. 1987. A protein required for splicing group I introns in Neurospora mitochondria is mitochondrial tyrosyl-tRNA synthetase or a derivative thereof. Cell 50: 331-345.

Bassi, G.S., de Oliveira, D.M., White, M.F., and Weeks, K.M. 2002. Recruitment of intron-encoded and co-opted proteins in splicing of the bI3 group I intron RNA. Proc. Natl. Acad. Sci. 99: 128-133.

Bolduc, J.M., Spiegel, P.C., Chatterjee, P., Brady, K.L., Downing, M.E., Caprara, M.G., Waring, R.B., and Stoddard, B.L. 2003. Structural and biochemical analyses of DNA and RNA binding by a bifunctional homing endonuclease and group I intron splicing factor. Genes \& Dev. 17: 2875-2888.

Caprara, M.G., Lehnert, V., Lambowitz, A.M., and Westhof, E. 1996. A tyrosyl-tRNA synthetase recognizes a conserved tRNA-like structural motif in the group I intron catalytic core. Cell 87: 1135-1145.

Chatterjee, P., Brady, K.L., Solem, A., Ho, Y., and Caprara, M.G. 2003.
Functionally distinct nucleic acid binding sites for a group I intron encoded RNA maturase/DNA homing endonuclease. J. Mol. Biol. 329: 239-251.

Chevalier, B.S. and Stoddard, B.L. 2001. Homing endonucleases: Structural and functional insight into the catalysts of intron/intein mobility. Nucleic Acids Res. 29: 3757-3774.

Dalgaard, J.Z., Klar, A.J., Moser, M.J., Holley, W.R., Chatterjee, A., and Mian, I.S. 1997. Statistical modeling and analysis of the LAGLIDADG family of site-specific endonucleases and identification of an intein that encodes a site-specific endonuclease of the HNH family. Nucleic Acids Res. 25: 4626-4638.

Delahodde, A., Goguel, V., Becam, A.M., Creusot, F., Perea, J., Banroques, J., and Jacq, C. 1989. Site-specific DNA endonuclease and RNA maturase activities of two homologous intron-encoded proteins from yeast mitochondria. Cell 56: 431-441.

Dujardin, G., Jacq, C., and Slonimski, P.P. 1982. Single base substitution in an intron of oxidase gene compensates splicing defects of the cytochrome $b$ gene. Nature 298: 628-632.

Geese, W.J., Kwon, Y.K., Wen, X., and Waring, R.B. 2003. In vitro analysis of the relationship between endonuclease and maturase activities in the bi-functional group I intron-encoded protein, IAniI. Eur. J. Biochem. 270: 1543-1554.

Goguel, V., Delahodde A., and Jacq, C. 1992. Connections between RNA splicing and DNA intron mobility in yeast mitochondria: RNA maturase and DNA endonuclease switching experiments. Mol. Cell. Biol. 12: 696-705.

Golden, B.L., Gooding, A.R., Podell, E.R., and Cech, T.R. 1998. A preorganized active site in the crystal structure of the Tetrahymena ribozyme. Science 282: 259-264.

Harrison, R.G. 2000. Expression of soluble heterologous proteins via fusion with NusA protein. Innovations 11: 4-7.

Henke, R.M., Butow, R.A., and Perlman, P.S. 1995. Maturase and endonuclease functions depend on separate conserved domains of the bifunctional protein encoded by the group I intron aI $4 \alpha$ of yeast mitochondrial DNA. EMBO J. 14: 5094-5099.

Herbert, C.J., Labouesse, M., Dujardin, G., and Slonimski, P.P. 1988. The NAM2 proteins from S. cerevisiae and S. douglasii are mitochondrial leucyl-tRNA synthetases, and are involved in mRNA splicing. EMBO J. 7: 473-483.

Ho, Y. and Waring, R.B. 1999. The maturase encoded by a group I intron from Aspergillus nidulans stabilizes RNA tertiary structure and promotes rapid splicing. J. Mol. Biol. 292: 987-1001.

Jamoussi, K. and Lazowska, J. 2000. Intragenic suppressors that restore the splicing and homing activities of the protein encoded by the second intron of the Saccharomyces capensis cyt b gene. Curr. Genet. 38: 276-282.

Jeffery, C.J. 2003. Moonlighting proteins: Old proteins learning new tricks. Trends Genet. 19: 415-417.

Labouesse, M., Herbert, C.J., Dujardin, G., and Slonimski, P.P. 1987. Three suppressor mutations which cure a mitochondrial RNA maturase deficiency occur at the same codon in the open reading frame of the nuclear NAM2 gene. EMBO J. 6: 713-721.

Lambowitz, A.M. and Perlman, P.S. 1990. Involvement of aminoacyltRNA synthetases and other proteins in group I and group II intron splicing. Trends Biochem. Sci. 15: 440-444.

Lambowitz, A.M., Caprara, M.G., Zimmerly, S., and Perlman, P.S. 1999. Group I and group II ribozymes as RNPs: Clues to the past and guides to the future. In The RNA world, $2 \mathrm{~d}$ ed. (eds. R.F. Gesteland et al.) pp. 451-485. Cold Spring Harbor Laboratory Press, Cold Spring Harbor, NY.

Li, G.-Y., Becam, A.-M., Slonimski, P.P., and Herbert, C.J. 1996. In vitro mutagenesis of the mitochondrial leucyl tRNA synthetase of Saccharomyces cerevisiae shows that the suppressor activity of the mutant proteins is related to the splicing function of the wild-type protein. Mol. Gen. Genet. 252: 667-675.

Myers, C.A., Kuhla, B., Cusack, S., and Lambowitz, A.M. 2002. tRNAlike recognition of group I introns by a tyrosyl-tRNA synthetase. Proc. Natl. Acad. Sci. 99: 2630-2635.

Rho, S.B., Lincecum Jr., T.L., and Martinis, S.A. 2002. An inserted 
region of leucyl-tRNA synthetase plays a critical role in group I intron splicing. EMBO J. 21: 6874-6881.

Rose, M.A. and Weeks, K.M. 2001. Visualizing induced fit in early assembly of the human signal recognition particle. Nat. Struct. Biol. 8: 515-520.

Saldanha, R.J., Patel, S.S., Surendran, R., Lee, J.C., and Lambowitz, A.M. 1995. Involvement of Neurospora mitochondrial tyrosyltRNA synthetase in RNA splicing. A new method for purifying the protein and characterization of physical and enzymatic properties pertinent to splicing. Biochemistry 34: 1275-1287.

Solem, A., Chatterjee, P., and Caprara, M.G. 2002. A novel mechanism for protein-assisted group I intron splicing. RNA 8: 412-425.

Szczepanek, T., Jamoussi, K., and Lazowska, J. 2000. Critical base substitutions that affect the splicing and/or homing activities of the group I intron bi2 of yeast mitochondria. Mol. Gen. Genet. 264: 137-144. 

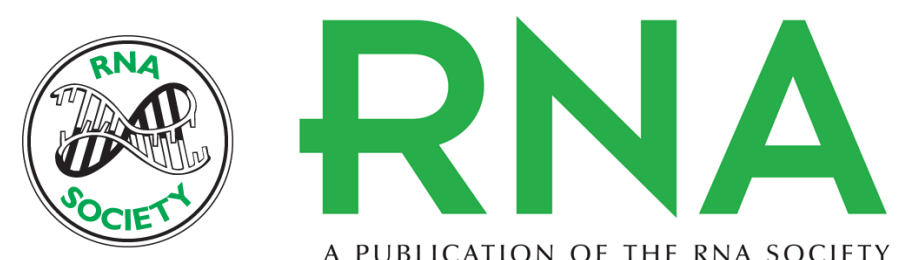

A PUBLICATION OF THE RNA SOCIETY

\section{A C-terminal fragment of an intron-encoded maturase is sufficient for promoting group I intron splicing}

MAUREEN E. DOWNING, KRISTINA L. BRADY and MARK G. CAPRARA

RNA 2005 11: 437-446

References This article cites 28 articles, 7 of which can be accessed free at:

http://rnajournal.cshlp.org/content/11/4/437.full.html\#ref-list-1

\section{License}

Email Alerting Receive free email alerts when new articles cite this article - sign up in the box at the Service top right corner of the article or click here.

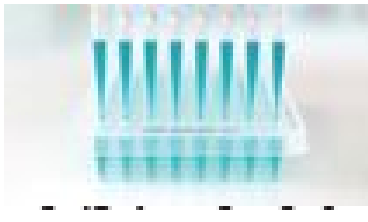

Providing Precise Solutions for your research.

To subscribe to RNA go to:

http://rnajournal.cshlp.org/subscriptions 